\title{
Unexpected presence of cytokeratins in human "glia-like" cells
}

\author{
Sivakova I, Perzelova A, Kubikova E, Mraz P \\ Department of Anatomy, School of Medicine, Comenius University, Bratislava, Slovakia. \\ Ivana.sivakova@fmed.uniba.sk
}

\begin{abstract}
Objectives: To demonstrate the unexpected features of the predominant cell population in adult human brain tissue cultures usually termed "glia-like" cells.

Background: Cytokeratins (CK) are intermediate filaments (IF) specific for normal and neoplastic epithelial cell differentiation.

Methods: We examined adult human brain tissue cultures and cryosections prepared from ten biopsies. Immunofluorescence staining with monoclonal antibodies against IF proteins: anti-pan CK, glial fibrillary acidic protein (GFAP) and vimentin was performed on primary and secondary cultures up to passage 10.

Results: In primary cultures we detected only small numbers of immunocytochemically distinct astrocytes, oligodendrocytes and microglial cells. "Glia-like" cells were negatively stained with specific glial marker antibodies. They were positively stained with pan-CK antibodies in 8/10 cultures where $0.1 \%$ to $70 \%$ CK-positive cells were present in primary as well as in secondary cultures. Comparative immunofluorescence IF staining for CK, GFAP and vimentin showed differences in the cytoplasmatic distribution of IF fibres, numbers of positive cells and intensities of staining. Cryosections from brain biopsies stained negatively with pan-CK antibodies.

Conclusion: These findings demonstrate the presence of CK in adult human brain cultures which is not caused by cross-reactivity of IF antibodies. Based on these results we propose that unexpected CK expression in human "glia-like" cells is due to cell dedifferentiation under culture conditions (Tab. 1, Fig. 2, Ref. 24). Full Text in PDF www.elis.sk.

Key words: intermediate filaments, GFAP, cytokeratins, vimentin, fibronectin.
\end{abstract}

IF are one of three types of cytoskeletal fibres in eukaryotic cells, having an average diameter of $10 \mathrm{~nm}$. They may be divided into chemically distinct classes: Types I and II - acidic and basic keratins; Type III - desmin, vimentin, GFAP and peripherin, Type IV - neurofilaments and related filaments, Type V-laminins, and Type VI - nestin $(1,2,3)$. They play an important role as structural and functional proteins of the cytoskeleton. In addition, immunocytochemical examination of IF proteins shows distinct expression patterns in diverse normal and cancer cell types $(4,5,6)$. For example, glial fibrillary acidic protein (GFAP) is specifically expressed in cells of astroglial origin, neurofilaments in neurons and desmin in muscle. Keratins are abundant proteins in epithelial cells, and vimentin was initially considered to be a specific marker for mesenchymal cells $(7,8)$.

Pontén and Westermark (9) coined the term "glia-like" cells for a predominant cell population in adult human brain tissue cul-

Department of Anatomy, School of Medicine, Comenius University, Bratislava, Slovakia

Address for correspondence: I. Sivakova, Department of Anatomy, School of Medicine, Comenius University, Sasinkova 2, SK-813 72 Bratislava, Slovakia.

Phone: +421.2.59357424, Fax: +421.2.59357321

Acknowledgements: We would like to thank Dr. R. MacLeod for critical reading and linguistic correction of the manuscript. We also thank Mrs. Hillova, Mrs. Skopekova and Mr. Miklos for technical assistance. This study was supported by VEGA grant No 1/0534/03, and League against Cancer in Slovakia. tures containing any or small amounts of stainable GFAP. Most of immunocytochemical studies use GFAP as the best marker for astrocytes under normal and pathological conditions $(10,6,11)$. However, human brain tissue cultures contain only a small percentage of GFAP-positive astrocytes in early passages (12, 13, $14)$. On the other hand, some authors have shown a high percentage of flat GFAP-positive stained cells in adult human brain cultures $(15,16)$. Others suggest that "glia-like" cells are non-glial in origin $(13,17)$. The discrepancies in reports concerning GFAP immunostaining as well as the unclear origin of "glia-like" cells remain to be resolved. In this study we provide further characterization of "glia-like" cells in relation to cell dediferentiation under culture conditions.

\section{Materials and methods}

\section{Tissue cultures}

Over the past two decades we have been interested in adult human glia culturing using brain biopsies kindly provided by the Department of Neurosurgery, Derer's Hospital, Bratislava. Experiments with human brain biopsies were performed according to Slovak Laws 272/1994, 76/2004 and approved by the Ethical Committee of UNB Bratislava. Once established, tissue cultures were frozen and stored at primary and early passages. For this study we chose ten tissue cultures from adult donors (21-69 years old) who had undergone neurosurgical intervention for brain trauma, aneurism or stroke. The samples were obtained from temporal or 
frontal lobes. Tissue cultures were prepared separately from cortical gray and white matter. Samples were cut into small pieces, less than $1 \mathrm{~mm}^{3}$ and seeded into plastic uncoated Petri dishes in medium consisting of MEM enriched with $10 \%$ fetal calf serum, glutamine, and non-essential amino acids. Cultures were passaged using $0.2 \%$ EDTA and $0.25 \%$ trypsin up to passage number 10 . Cells used for immunofluorecence staining were grown under the same conditions on uncoated glass coverslips.

\section{Immunofluorescence}

To characterize the glial cell types we used the same marker antibodies as described previously $(14,18)$, particularly, GFAP for astrocytes, $\mathrm{O} 4$ for oligodendrocytes, and CD11c for microglia/ macrophages. Indirect immunofluorescence was used for identification of glial cell types, IF proteins and fibronectin in primary and secondary cultures up to passage number 10 .

The cells grown on uncoated glass coverslips were rinsed with phosphate-buffered saline (PBS) and fixed in methanol-acetone (1:1) solution for 15 minutes at $-15^{\circ} \mathrm{C}$. The staining was performed with monoclonal anti-pan CK $(1,4,5,6,8,10,13,18,19$, Sigma), monoclonal to GFAP (clone G-A-5) to vimentin (clone V9) and polyclonal sera to fibronectin and GFAP. CD11c and O4 antigens were examined on cells fixed in $4 \%$ p-formaldehyde. The fixed cells were incubated for 1 hour with primary and for 30 minutes with 1:50 diluted secondary antibodies as appropriate.

Double labeling for CK/fibronectin and CK/GFAP was performed with primary, and afterwards with appropriate mixtures of secondary antibodies for 1 hour and 30 minutes, respectively. To determine the percentages of CK-positive cells, 50 fields were enumerated at $400 \mathrm{x}$ magnification, equally distributed over the coverslips fixed at 3 DIV in primary and secondary cultures during passages number 10 .

The same bioptic brain biopsies were used for tissue and cultures examinations. Staining with monoclonal anti-pan CK was performed on $10-\mu \mathrm{m}$ thick cryosections using the same fixation and indirect immunofluorescence method as described above. Fluorescence microscopy was performed with an Olympus IMT2 microscope.

\section{Results}

\section{Immunofluorescence staining}

The results of indirect immunofluorescence staining for GFAP, vimentin, fibronectin and $\mathrm{CK}$ are summarized in Table 1.

\section{Glial cells}

The staining with glial marker antibodies was performed on primary and secondary cultures up to passage number 5. Indirect immunofluorescence and glial marker antibodies were used to identify the glial cell types. We detected only a small amount of astrocytes $(0.1 \%)$, oligodendrocytes $(0.01 \%)$ and microglia/ macrophages $(2-5 \%)$ in confluent primary cultures. All glial cell types disappeared in early passages up to number 4 . Indirect immunofluorescence showed that process-bearing glial cells and microglia/macrophages with grainy or vaculolated cytoplasm were
Tab. 1. Quantitative analysis of immunofluorescence staining on human "glia-like" cells. Percentage (\%) of positive cells and intensity of staining.

\begin{tabular}{lcccc}
\hline Tissue cultures & CK & GFAP & Vimentin & Fibronectin \\
\hline $78-\mathrm{NM}$ & $35-42++,+++$ & 0 & $100+++$ & $100+++$ \\
91-NM & $1-3++$ & 0 & $100+++$ & $100+++$ \\
93-NM & $58-67++,+++$ & 0 & $100+++$ & $<95+,++$ \\
$111-\mathrm{NM}$ & 0 & 0 & $100+++$ & $100+++$ \\
$124-\mathrm{NM}$ & $0.5-2++$ & 0 & $100+++$ & $100+++$ \\
$195-\mathrm{NM}$ & $64-70++,+++$ & 0 & $100+++$ & $<95+,++$ \\
$208-\mathrm{NM}$ & $1-2++$ & 0 & $100+++$ & $100+++$ \\
$242-\mathrm{NM}$ & $30-45++,+++$ & 0 & $100+++$ & $100+++$ \\
$569-\mathrm{NM}$ & 0 & 0 & $100+++$ & $100+++$ \\
$597-\mathrm{NM}$ & $25-37++,+++$ & 0 & $100+++$ & $100+++$ \\
\hline
\end{tabular}

Intensity of staining: + low, ++ moderate, +++ strong

always negatively stained with pan-CK antibodies (Fig. 1A, B). The double labeling for GFAP/CK confirmed the negative staining of rarely GFAP-positive astrocytes in early passages.

\section{"Glia-like" cells}

The cells in primary as well as in secondary cultures up to passage number 10 were examined for vimentin, fibronectin and $\mathrm{CK}$. The predominant cell polupation of flat "glia-like" cells were negatively stained for GFAP, and positively for vimentin and fibronectin. Positive staining with pan-CK monoclonal antibodies was found in $8 / 10$ cultures in which the $0.1 \%$ to $70 \%$ CK positive cells were present. Similar percentages of CK-positive cells were observed in primary as well as in secondary cultures (Figs 1A, B, E). Immunostaining showed a clear fibrillary structure of positively stained cells. At confluence, areas of CK-positive cells were observed (Fig. 1E). Rarely they occurred as single cells (Fig. $1 \mathrm{C}, \mathrm{D})$. Comparative analysis of indirect immunofluorescence staining for vimentin and $\mathrm{CK}$ showed differences in cytoplasmic distribution of both intermediate filaments. Vimentin fibres were distributed rather equally (Fig. 1F), while CK were often found as concentrated fibres near the nucleus or unequally distributed in the cytoplasm (Fig. 1C, E). In two cultures with high percentages of CK-positive cells, the double labeling for CK and fibronectin showed moderate intensity of extra-, and intra-cellular staining for fibronectin (Fig. 2A, B, C), while in cultures containing any or lower percentage of CK-positive cells the intensity showed to be strong (Fig. 2D, E). No differences were observed in CK, vimentin and fibronectin immunostaining in cultures derived from cortical gray and white matter.

\section{Discussion}

In this study we found an unexpected presence of CK-positive staining in human "glia-like" cells. To our knowledge, CK expression has not been described so far in adult human brain tissue cultures. Cultures and cryosections were prepared from ten human brain bioptic samples from adult patients who had undergone neurosurgical intervention for brain trauma, aneurism or stroke. CK were present in 8/10 examined tissue cultures which contained different percentages $(0.1$ to $70 \%)$ of CK-positively 

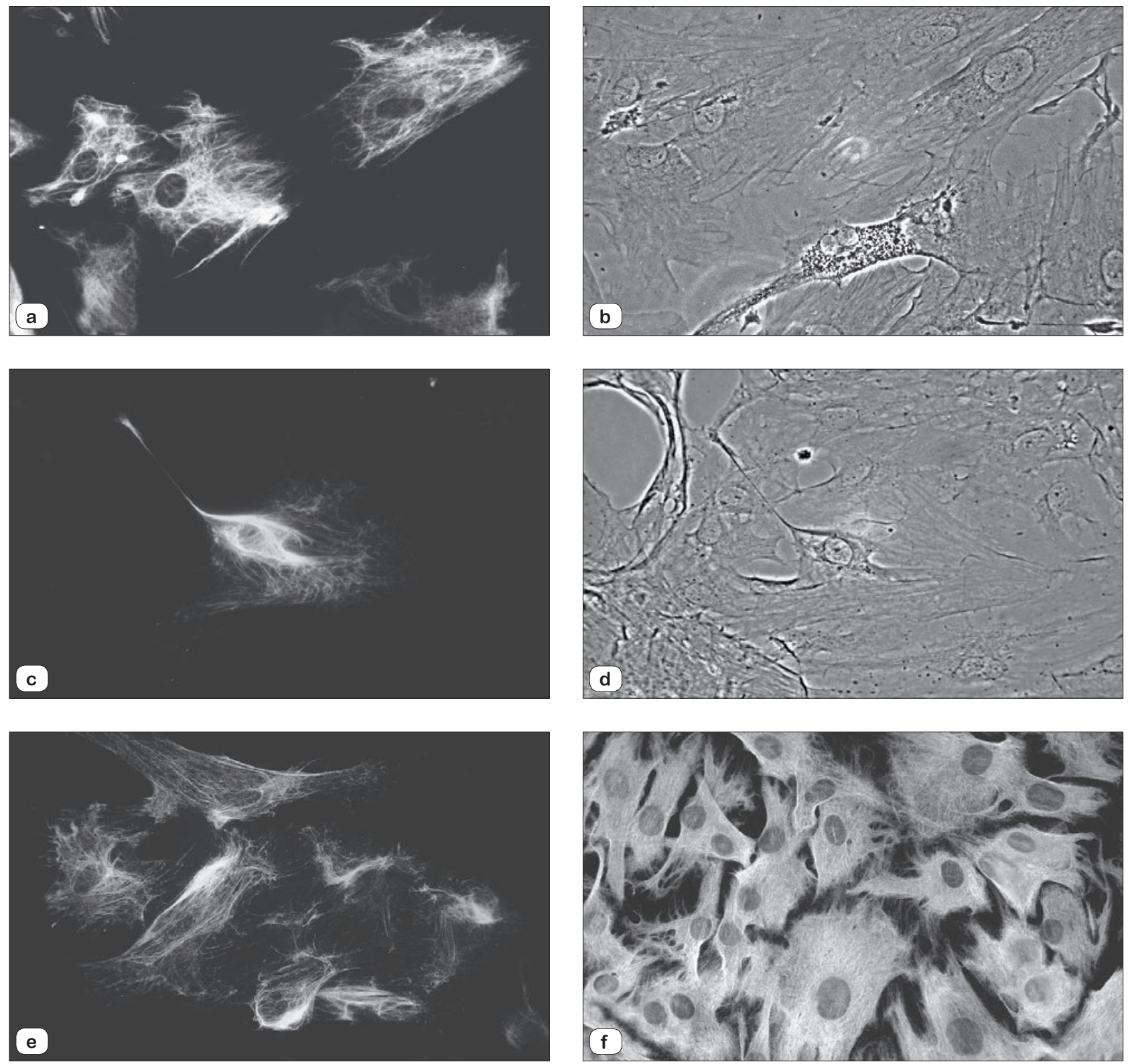

Fig. 1. Indirect immunofluorescence staining for CK and vimentin in adult human "glia-like" cells. (A) Area of CK-positive cells in primary cultures. (B) Phase-contrast microscopy. Note: One microglia/macrophage with grainy cytoplasm, negatively stained for CK. (C) Single CKpositive cell, passage 5. (D) Phase-contrast microscopy. (E) CK-positive cells with specific distribution of CK fibres, passage 5. (F) Vimentin positive cells with equally distributed fibres, passage 5 . Scale bar $=\mathbf{5 0}$ um.

stained cells. We suppose that the big differences in percentage of CK-positively stained cells are triggered in the damaged brain tissue and expressed under culture conditions. In addition, the cultures were examined for vimentin, GFAP and fibronectin. All "glia-like" cells were negatively stained for GFAP and positively for vimentin and fibronectin. Double immunofluorescence labeling showed remarkable co-expression for $\mathrm{CK}$ and fibronectin, moderate intensity of staining for fibronectin in two cultures with high percentage of CK-positive cells and strong intensity in remaining cultures.
CK-positive staining was demonstrated in gliomas with various degree of malignancy $(19,20,21)$. We demonstrated the presence of CK in two recently established glioblastoma 8-MG-BA and 42-MG-BA and in clonal GL-15 cell lines $(22,23)$. However, some authors indicated that positive staining for $\mathrm{CK}$ in gliomas is due to cross-reactivity of antibodies with non-keratin proteins such as GFAP (24). Previously we demonstrated that CK-positive staining in gliomas is not caused by cross-reactivity of IF antibodies (22). In this study, the cytoplasmic distribution of IF was clearly different for vimentin and $\mathrm{CK}$, thus providing evidence 

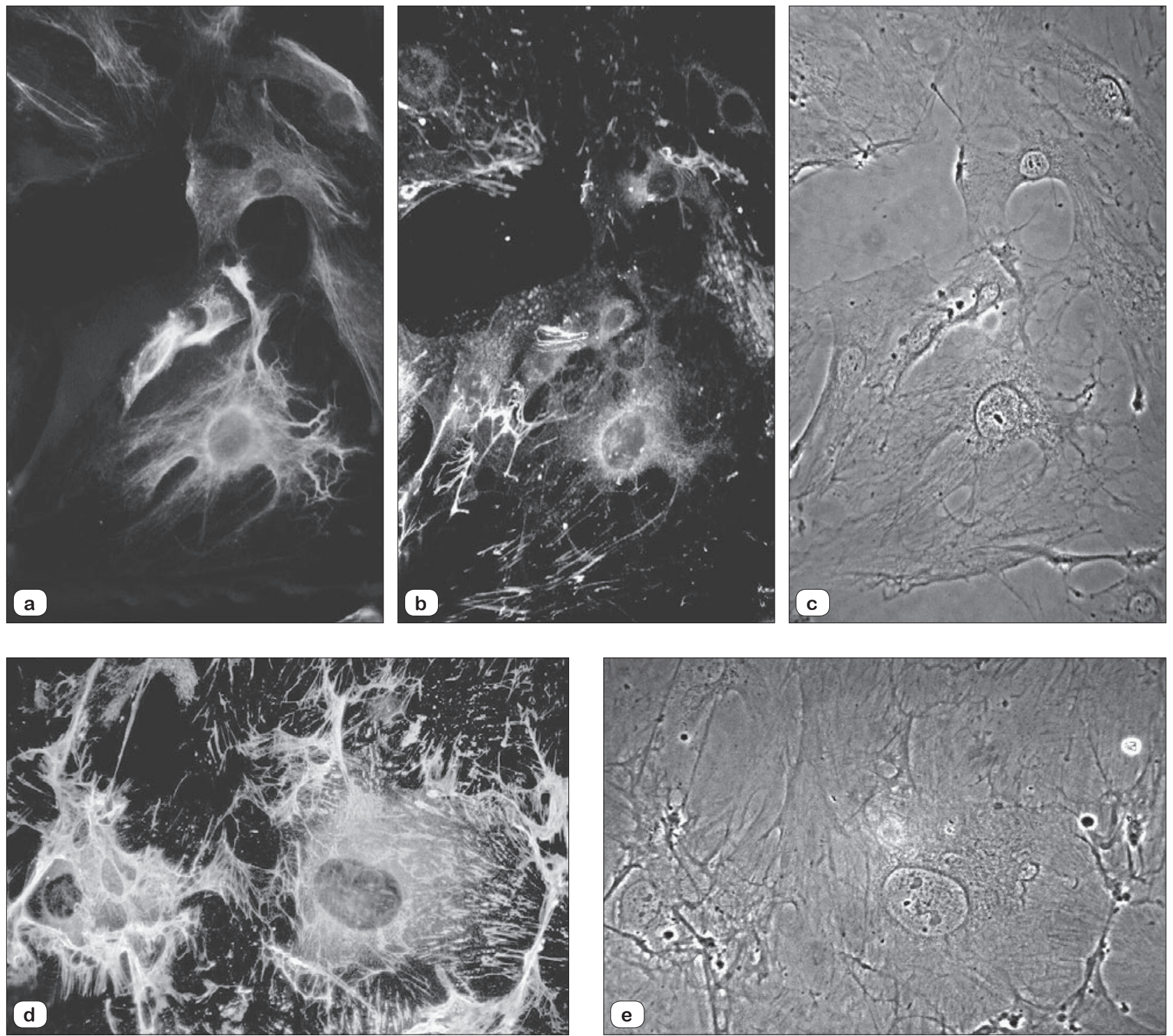

Fig. 2. Double labeling for CK and fibronectin in adult human "glia-like" cells. (A-C) The culture with high percentage of CK-positive cells and moderate intensity of extra and intra-cellular stainings for fibronectin, passage 10. (A) CK-positive cells. (B) Fibronectin positivity. (C) Phase-contrast microscopy. (D-E) The culture without CK-positive cells and strong fibronectin staining, passage 10.(D) Fibronectin positive cells. (E) Phase-contrast microscopy. Scale bar $=50$ um.

that there is no cross reactivity of antibodies against IF proteins. On the other hand, negative staining with pan-CK antibodies was observed in adult human brain cryosections which were prepared from the same bioptic samples as tissue cultures using the same immunofluorescence methods, antibodies and fixation.

Based on these findings we demonstrate that culture conditions may induce cell dedifferentiation in relation to positive expression of CK. An important role in cell dedifferentiation may be played by the fact that epithelial and brain tissues share a common ectodermal origin. In addition, these results draw attention to the risk of misinterpreting IF as cell type-specific protein under culture conditions.

\section{References}

1. Frederiksen K, McKay RDG. Proliferation and differentiation of rat neuroepithelial precursor cells in vivo. J Neurosci 1988; 8: 1144-1151.

2. Steinert PM, Jones JCR, Goldman RD. Intermediate filaments. J Cell Biol 1984; 99: 22-27.

3. Nagle RB. A review of intermediate filament biology and their use in pathologic diagnosis. Mol Biol Rep 1994; 19: 3-21.

4. Yang HY, Lieska N, Shao D, Kriho V, Pappas GD. Proteins of the intermediate filament cytoskeleton as markers for astrocytes and human astrocytomas. Mol Chem Neuropatol 1994; 22: 155-176. 
5. Ho CL, Liem RKH. Intermediate filaments in the nervous system: Implications in cancer. Cancer Metastasis Rev 1996; 15: 483-497.

6. Rutka JT, Murakami M, Dirks PB, Hubbard SL, Becker LE, Fukuyama K, Jung S, Tsugu A, Matsuzawa. Role of glial filaments in cells and tumors of glial origin: a review. J Neurosurg 1997; 87: 420-430.

7. Frank ED, Warren L. Aortic smooth muscle cells contain vimentin instead of desmin. Proc Natl Acad Sci USA 1981; 78: 3020-4.

8. Osborn M. Intermediate filaments as histologic markers: an overview. J Invest Dermatol 1983; 81: 104-9.

9. Ponten J, Westermark B. Properties of human malignant glioma cells in vitro. Med Biol 1978; 56: 184-193.

10. Bignami A, Eng LF, Dahl D, Uyeda CT. Localization of the glial fibrillary acidic protein in astrocytes by immunofluorescence. Brain Res 1972; 43: 429-435.

11. Davies DL, Niesman IR, Boop FA, Phelan KD. Heterogeneity of astroglia cultured from adult human temporal lobe. Int J Devl Neurosci 2000; 18: 151-160.

12. Osborn M,Ludwig-Festl M, Weber K, Bignami A, DahID, Bayreuther K. Expression of glial and vimentin type intermediate filaments in cultures derived from human glial material. Differentiation 1981; 19: 161-167.

13. Rutka JT, Kleppe-Hoifodt H, Emma DA, Giblin JR, Dougherty DV, McCulloch JR, DeArmond SJ, Rosenblum ML. Characterization of normal human brain cultures. Lab Invest 1986; 55: 71-85.

14. Perzelova A, Macikova I, Tardy M., Mraz P, Bizik I, Steno J. Subpopulation of nestin positive glial precursor cells occur in primary adult human brain cultures. Biologia 2007; 5: 633-640.

15. Estes ML, Ransohoff RM, McMahon JT, Jacobs BS, Barna BP. Characterization in adult human astrocytes derived from explant culture. J Neurosci Res 1990; 27: 697-705.
16. Van der Laan LJW, De'Groot CJA, Elices MJ, Dijkstra CD. Extracellular matrix protein expressed by human adult astrocytes in vitro and in vivo: an astrocyte surface protein containing the CS1 domain contributes to binding of lymphoblasts. J Neurosci Res 1997; 50: 539-548.

17. Gibbons HA, Hughes A, Van Roon-Mom W, Greenwood JA, Narayan PJ, Teoh H, Bergin PA, Mee EW, Wood PC, Faull RLM, Dragunov M. Cellular composition of human glial cultures from adult biopsy brain tissue. J Neurosci Meth 2007; 166: 89-98.

18. Macikova I, Perzelova A, Mraz P, Bizik I, Steno J. GFAP-positive astrocytes are rare or absent in primary adult human brain tissue cultures. Biologia 2009; 64: 833-839.

19. Mork SJ, Rubinstein LJ, Kepes JJ, Perentes E, Uphoff DF. Squamous differentiation of epithelial-like formations in gliosarcomas and glioblastomas. J Neuropathol Exp Neurol 1988; 47: 101-118.

20. Cosgrove M, Fitzgibbons PL, Sherrod A, Parakrama T, Chandrasoma PT, Martin SE. Intermediate filament expression in astrocytic neoplasm. Am J Surg Pathol 1989; 13: 141-145.

21. Hirato J, Nakazato Y, Ogawa A. Expression of non-glial intermediate filament proteins in gliomas. Clin Neuropathol 1994; 13: 1-11.

22. Macikova I, Perzelova A, Mraz P, Steno J, Bizik I. Heterogeneity of keratin intermediate filaments expression in human glioma cell lines. Neoplasma 1999; 46: 390-393.

23. Perzelova A, Macikova I, Tardy M, Mraz P, Steno J, Bizik I. Coexpression of GFAP, vimentin and cytokeratins in GL-15 glioblastoma cell line. Neoplasma 2000; 47: 362-366.

24. Kriho VK, Yang HY, Moskal JR, Skalli O. Keratin expression in astrocytomas: An immunofluorescent and biochemical reassessment. Virchows Arch 1997; 431: 139-147.

Received January 25, 2012. Accepted March 19, 2012. 